Historic, Archive Document

Do not assume content reflects current scientific knowledge, policies, or practices. 



\section{Edwards-Haile Co.}

Wholesale Contract Growers of

\section{WATERMELON SEEDS}

\section{CAR LOTS A SPECIALTY}

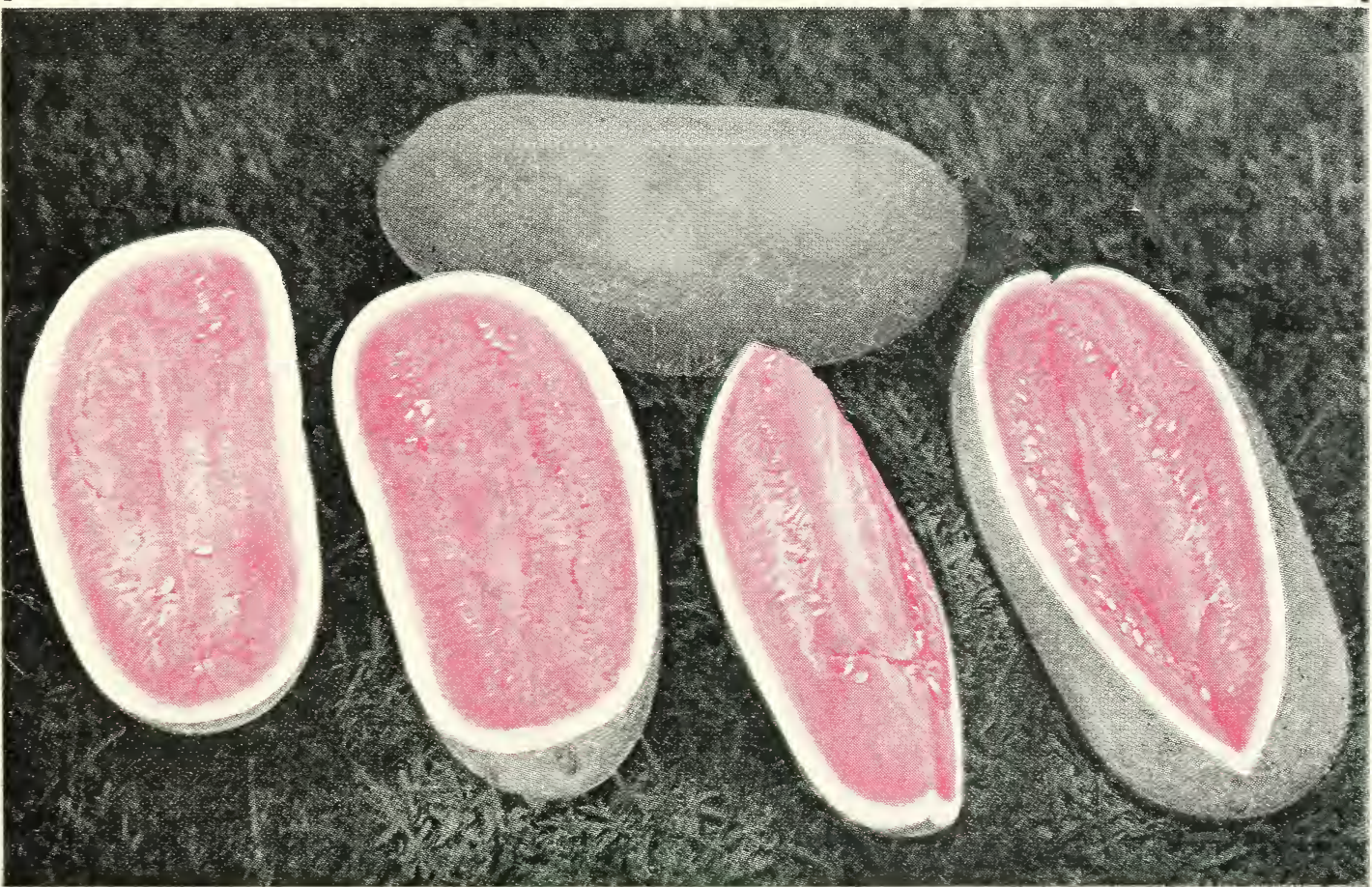

Announcing the Introduction of HAILE'S "IRISH GRAY"

A Distinct Variety and Improvement on the Original 1. Irish Gray. The Standard Name will be Haile's Gray. The Seed of this variety a Dark Brown, Meat Bright Red, Rind Greenish Gray and very tough. It is a Shipping Melon.

$1922 \quad:: \quad:: \quad:: \quad:$ : $\quad:$ : Cordele, Ga. 


\section{To Our Customers}

W E beg to announce that we operate at Monticello, Fla., a modern Seed Farm, growing, improving and breeding up different varieties of Water Melon Seeds.

Our varieties are all separated, no two different varieties being planted within one-half mile of each other.

Our seed stocks are distinctly improved and true to variety. The quality is the best.

Our growers are all capable, experienced men of many years' experience in growing these melons and saving the seed.

We have a complete Warehouse, Recleaning and Testing Department.

We cater to the Wholesale Trade exclusively and do not quote the Retail Trade.

We expect the Seed Jobbers to protect us on this point and give us their business in preference to growers who sell all and any class of the Seed Trade.

Our prices are low compared to the quality and service we give you.

Actual results speak louder than words, therefore we are giving you actual photographs of some of our growing fields showing you what we grow.

Yours very truly, 


\section{Haile's Gray}

\section{A NEW DISTINCT VARIETY}

\section{A Cross Between the Waison and Old Irish Gray}

NE of our oldest Georgia Growers of Melons has developed this melon and we will offer the seed for the first time to the trade after crop harvest in 1922.

We do not claim the distinction of originating this melon, but same was originated for us by one of our growers and we have the privilege of naming and introducing to the public.

This melon is a greenish gray, long shaped, grows to an average of thirty to forty pounds, has unusually tough rind, a bright red flesh and is very prolific.

The seed are a very dark brown, whereas the original Irish Gray has a white seed.

It is a distinct variety different from any melon now being grown and a decided improvement on the Irish Gray we are now planting.

The old Irish Gray is a fine melon, but as you know has a whitish gray color. This melon has a very greenish gray color, which makes the appearance more attractive, and, therefore, a better seller to the buyers.

It has all the qualities of the old Irish Gray and Tom Watson, its parents, and an improvement on keeping qualities.

We picked one of these melons in the field, put it under a bush and left it for thirty days. Wc went back, cut it and the rind or meat had not deteriorated a bit.

This melon will stay fresh a long time after all vines on the field are dried up.

Our grower shipped twenty-three cars from thirty acres, averaging twenty-six to thirtytwo pounds, and the price was fifty dollars per car more than the Irish Gray on the same track on the same market.

The originator of this melon is getting $\$ 4.00$ per pound from the growers for the market for another year for his seed, and next season will be the first that this variety will be planted generally, we look for this melon to be the FAVORITE of all shipping melons after sufficiently introduced. It would pay all Seed Concerns to feature this in their newest catalogue, photographs furnished on request.

We will book orders from a hundred acres of this variety only for 1922 delivery, none for 1921 delivery. 
Illustrations of Florida Favorite, the Finest Close-By Market Melon and for Table Use

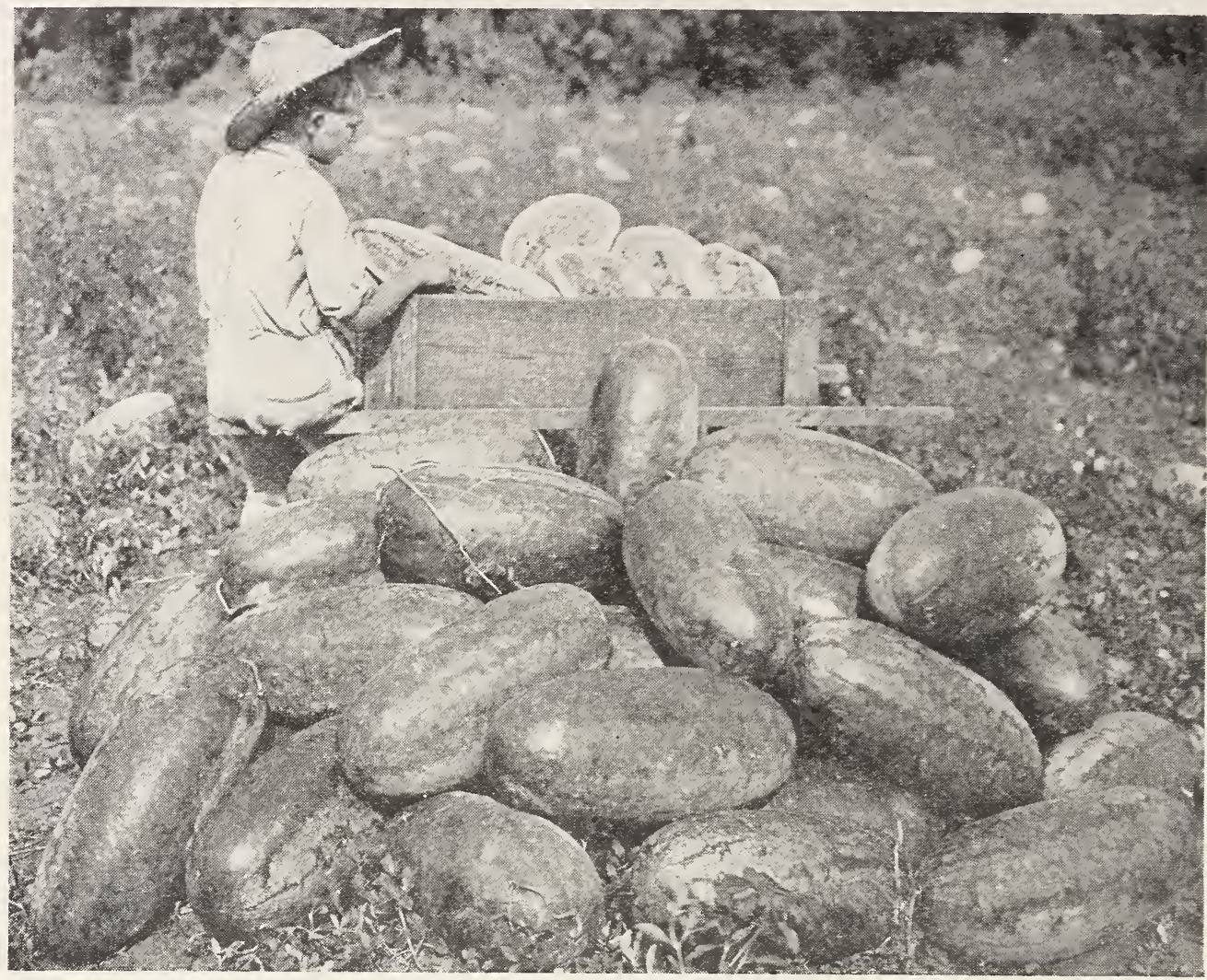

Please note the uniform size, color and shape of this variety. Can you beat it? We uon't think so.

Illustration of Our Improved Kleckley Sweets and Mr. Haile Enjoying the Heart of One of the Largest. Note the Uniform Size, Shape and Color of the Entire Field.

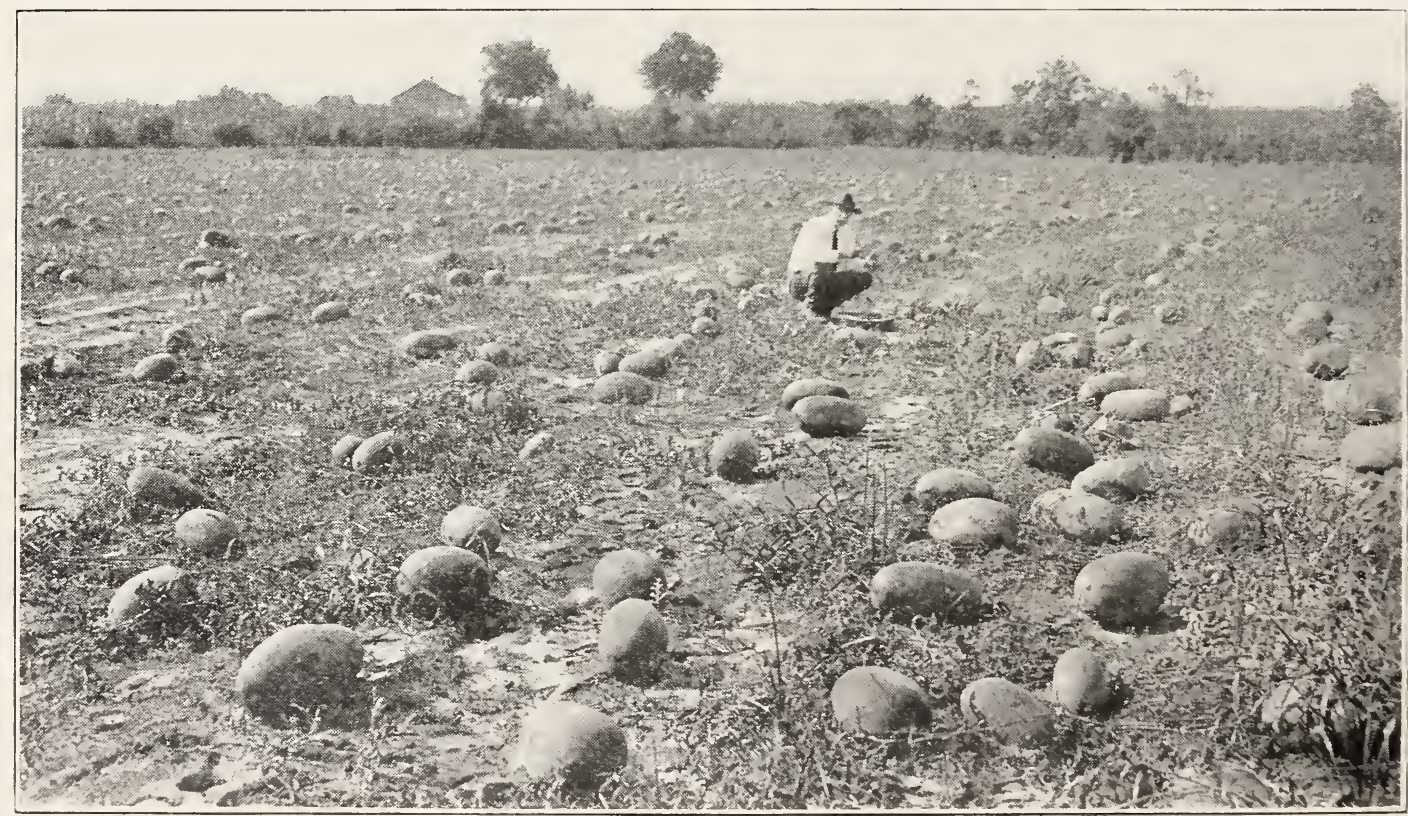

Our variety of Kleckley Sweets have reached the heighth of perfection, and we cannot grow them any better. Will not this make a big impression with you? It does with us. 
Illustrations of Field of Georgia Rattlesnake Melons-True to Type and a True to Type Florida Cracker, Eating a Large One.

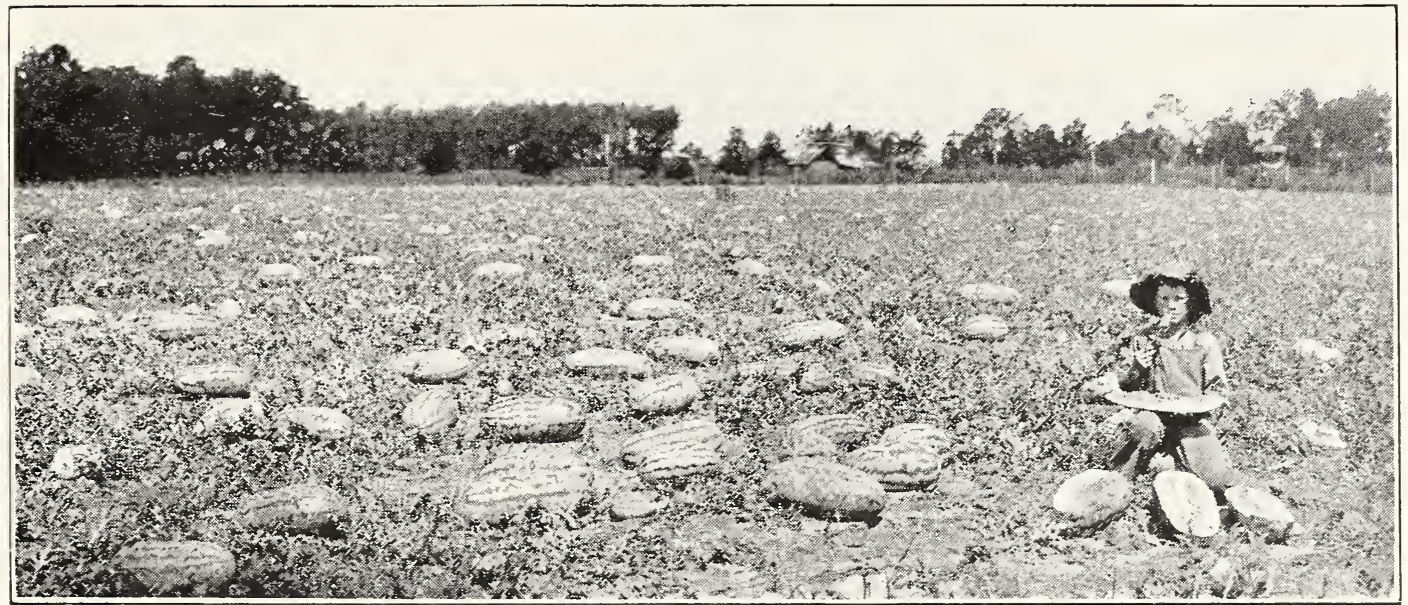

We want you to examine the type and average of this field of Georgia Rattlesnakes, they are the long variety, all properly colored and marked.

This shows breeding and improvement. We lend every effort to have our melons of purs strains and true to variety.

Illustration of One of Our Seed-Saving Machines and a Field of Tom Watson Variety. Mr. W. E. Haile Inspecting the Job.

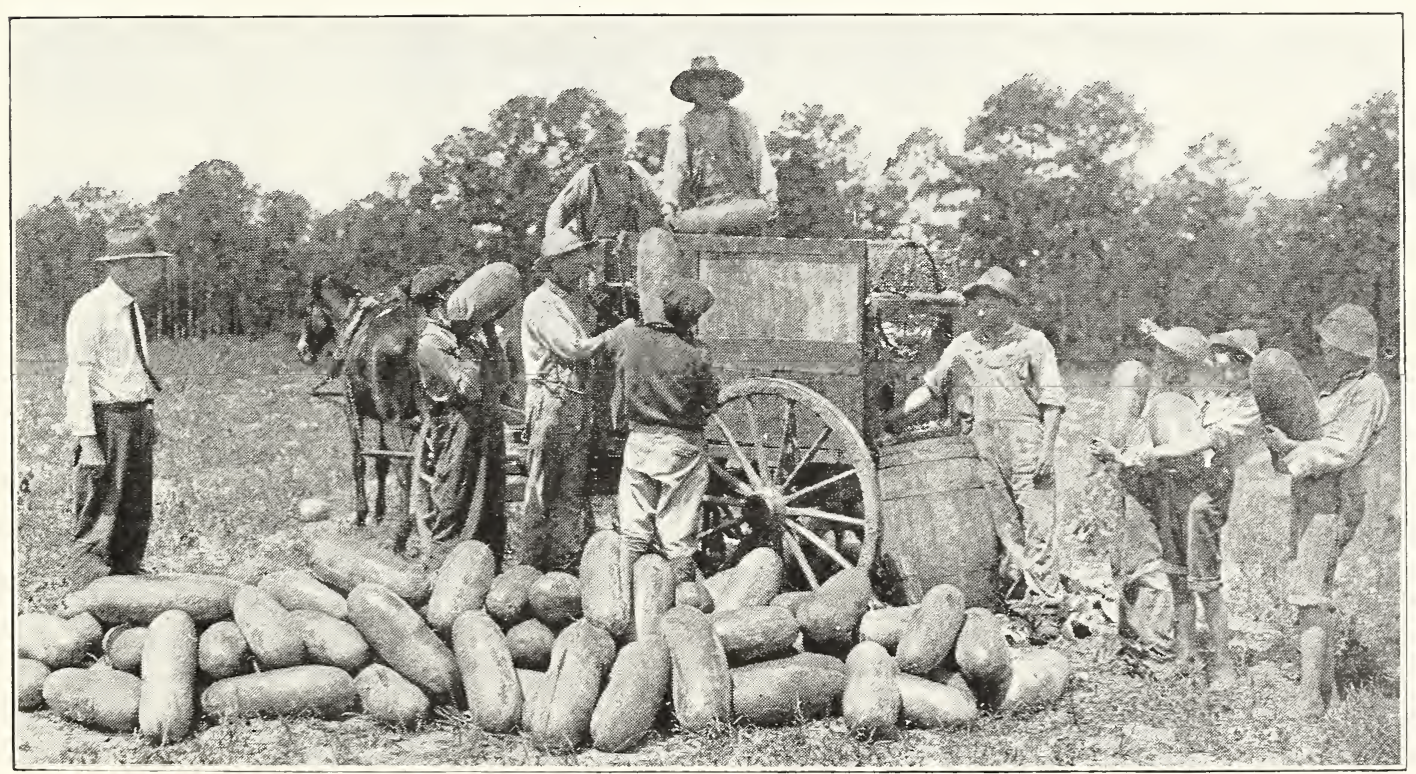

We have our own machines for separating rind and pulp from the seed. The melons are first piled in rows and the wagon with the machine eats them up as it goes along.

Two men turn this machine by hand and at night they will tell you that they have done a man's job. 
Illustration of a Field of Irish Gray. They Don't Grow Any Larger, Any Riper, Any Redder, or Any Sweeter Than They Do in North Florida at Monticello.

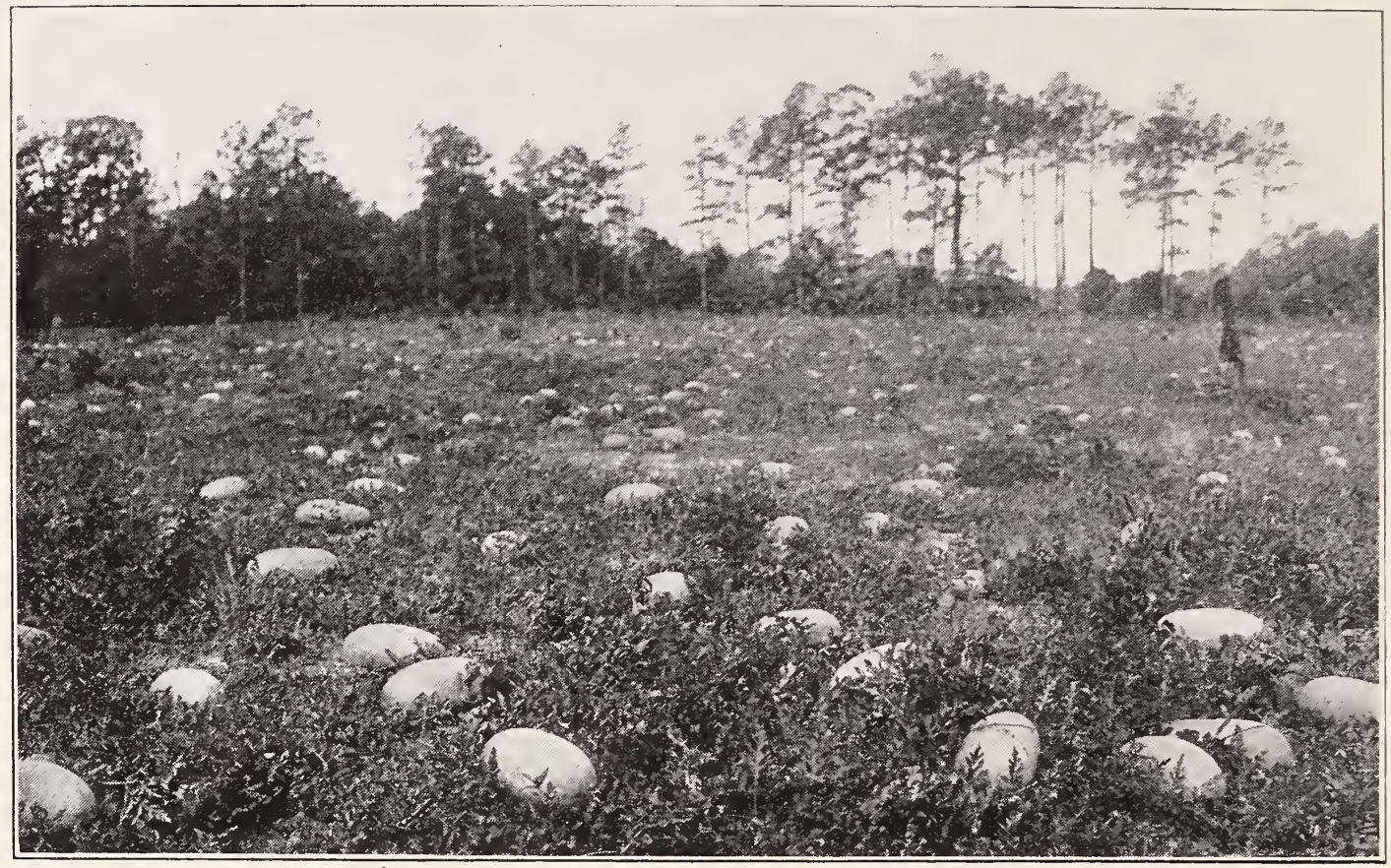

The 1921 season showed that the Irish Gray Melon as market melon and shipper was coming into popularity destined we believed to rival the old stand by viz. Tom Watson

Illustration of Field of Texas Wonder Water Melons.

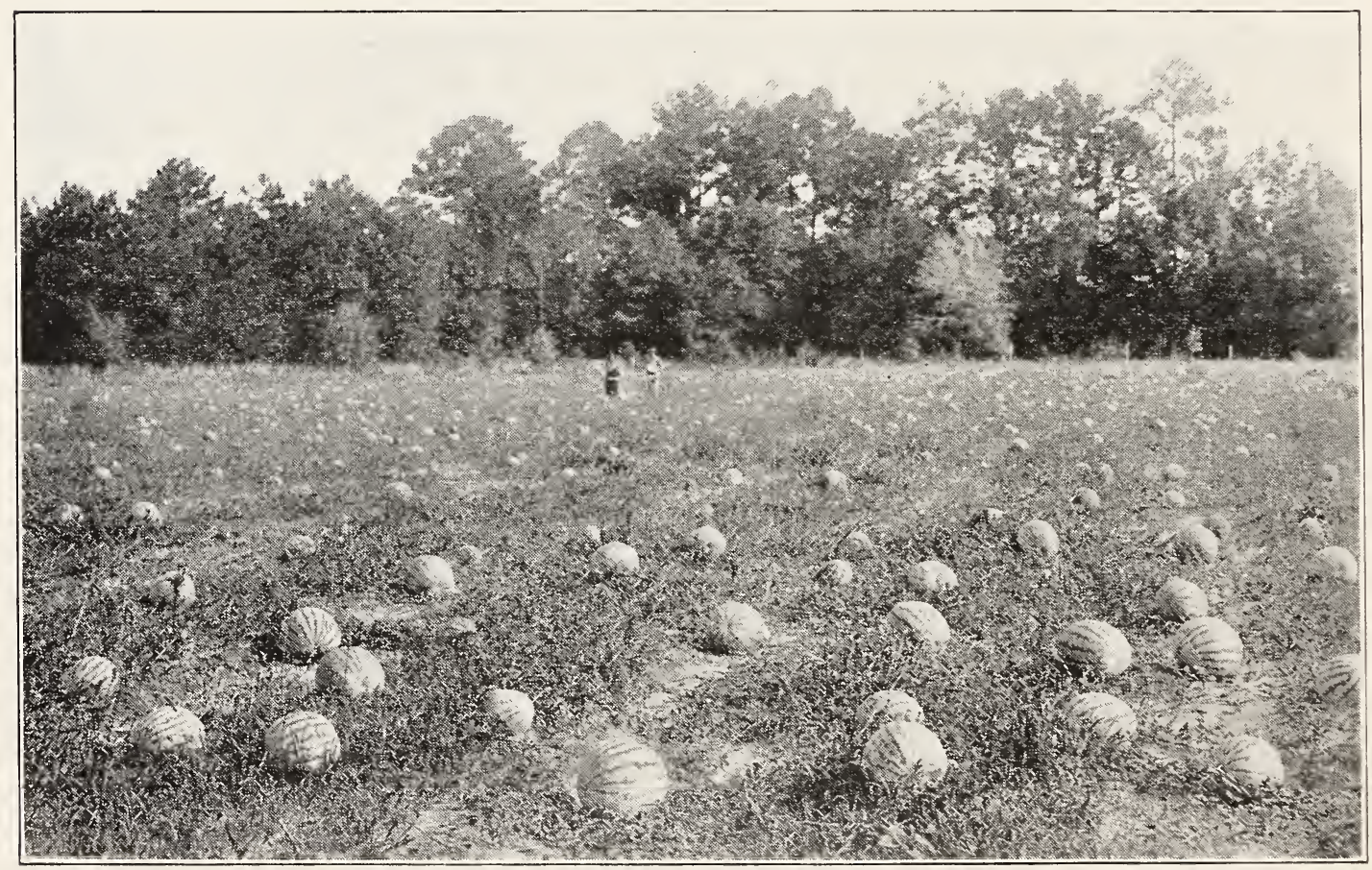

The seed for this field of melons was sent to us by one of our customers for us to grow for him. We carefully grew and cultivated same and you will note what a success we had. This melon grows very large and abundant. 
WE grow the following seeds and would like to have your business each year. These are none that will surpass our crops for quality:

Pearl or Cattail Millett.

Georgia Collard Seed.

Seed Chufas.

Early Speckled Velvet Beans.

Bunch Velvet Beans (a new introduction).

Cow Peas.

Fulghum Oats.

Red Valencia Peanut.

White Spanish Peanut.

Whatley's Prolific Seed Corn.

Hasting's Prolific Seed Corn.

Abruzzi Rye. will always give you rock-bottom prices.

We have two thousand acres in the above grown for us each year. Every item mentioned grown in the State of Georgia. We supply stock seed and see that our crops are grown and harvested right.

We specialize on car lots to the distributors and make close prices.

\section{FOR SEED JOBBERS ONLY}

LIST OF VARIETIES we can grow and furnish selected improved seed for.

Please send this sheet in with your requirements and we will quote you for delivery during 1922:

VARIETY.

QUANTITY.

PRICE.

Haile's Gray

Tom Watson

Kleckley Sweet

Alabama Sweet

Georgia Rattlesnake

Kolb Gem

Sweetheart

Peerless

Harris Early

Cole's Early

Cuban Queen

Halbert Honey

Fordhook Early

Dixie

Excel

Irish Gray

Duke Jones

Florida Favorite

Mt. Sweet

Triumph

Golden Sweet

Wonderful Sugar

Dark Icing

Light Icing

Pearson

Black Seeded Chilian

White Seeded Chilian

King and Queen

(Signed)

Address 


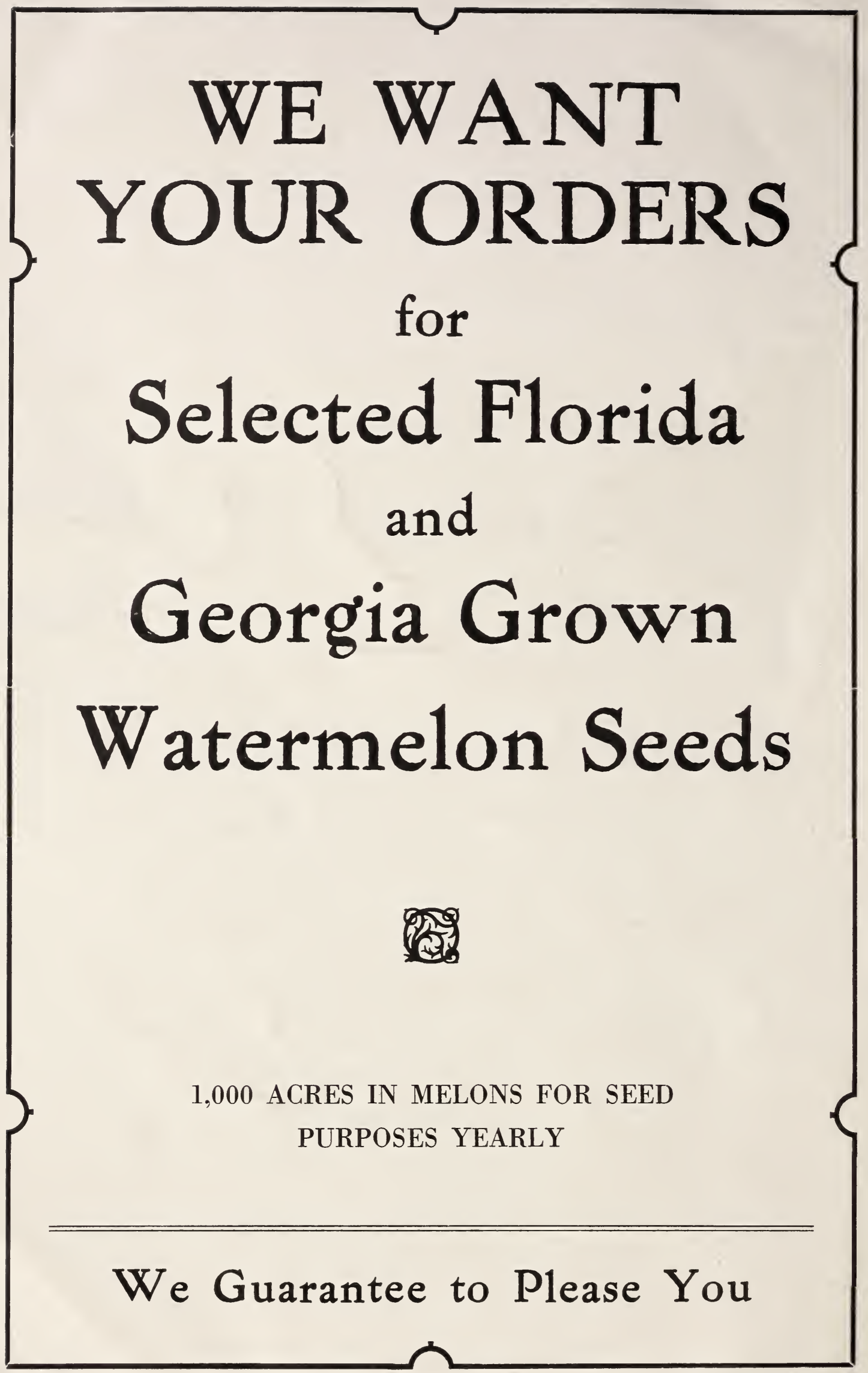

